\title{
A relação entre racismo, saúde e saúde mental: Psicologia e educação antirracista
}

The relationship between racism, health and mental health: Psychology and anti-racist education

\author{
Marcos Antonio Batista da Silva \\ Centro de Estudos Sociais, Universidade de Coimbra \\ Ivani Francisco de Oliveira \\ Universidade Cidade de São Paulo
}

\section{Resumo}

Neste artigo propomos uma discussão acerca do campo da Psicologia envolvendo a saúde mental e questões étnico-raciais, complementado pelo debate da educação das relações étnico-raciais. A Política Nacional de Saúde Integral da População Negra reconhece o racismo estrutural e as desigualdades étnico-raciais como determinantes sociais das condições de saúde. A revisão de literatura ancorada pelo referencial teórico-metodológico de raça, racismo e antirracismo, assim como da análise crítica de discurso, proporcionaram colocar em primeiro plano, debates e conflitos no que tangencia a população negra nas sociedades contemporâneas, em especial no Brasil. Conclui-se que devemos investir e insistir em culturas epistemológicas no campo da Psicologia e suas práticas que promovam avanços em debates sobre os efeitos do racismo na saúde mental da população negra, visando a promoção em saúde, equidade racial e ao combate ao racismo.

Palavras-chave: Educação Antirracista; Psicologia Clínica; Psicologia Social; Saúde Mental

\begin{abstract}
In this article, we propose a discussion about the field of Psychology involving mental health and ethnic-racial issues, complemented by the debate on the education of ethnic-racial relations. The National Policy for Comprehensive Health of the Black Population recognizes structural racism and ethnic-racial inequalities as social determinants of health conditions. The literature review anchored by the theoretical-methodological framework of race, racism and anti-racism, as well as critical discourse analysis, they have brought to the fore, debates and conflicts regarding the black population in contemporary societies, especially in Brazil. We conclude that we must invest and insist on epistemological cultures in the field of Psychology and its practices that promote advances in debates about the effects of racism on the mental health of the black population, aiming at promoting health, racial equity and combating racism.
\end{abstract}

Keywords: Anti-racist Education; Clinical Psychology; Social Psychology; Mental Health 


\section{INTRODUÇÃO}

Neste artigo propomos uma discussão sobre raça, racismo, antirracismo e saúde mental no que se refere à população negra na sociedade brasileira. 0 estudo está ancorado no debate realizado pelas Ciências ${ }^{1}$ Humanas e Saúde no campo da Psicologia (Santos et al.,2012), à luz das teorias de raça e racismo (Almeida, 2019; Faustino, 2017; Hall, 2003; Kilomba, 2019 Ramos, 1957; Werneck, 2016). Assim como da discussão das Diretrizes Curriculares Nacionais para a Educação das Relações étnico-raciais e ensino de História e Cultura Afrobrasileira e Africana - DCNERER (Conselho Nacional de Educação, 2004), e da Política Nacional de Saúde Integral da População Negra- PNSIPN (Ministério da Saúde, 2009).

No campo metodológico utilizamos a análise crítica do discurso de Teun van Dijk (2001). Segundo esse autor, a análise crítica do discurso "é uma pesquisa analítica do discurso que estuda (...) a maneira, como o abuso e a desigualdade do poder social são representados, reproduzidos, legitimados e resistidos pelo texto e pela fala no contexto social e político" (van Dijk, 2001, p. 466, tradução do inglês do autor). 0 método inclui na revisão de literatura sobre o tema proposto, a investigação de documentos de domínio público (legislações, documentos institucionais) objetivando colocar em primeiro plano debates, conflitos e desafios.

Deste modo, realizamos um levantamento sobre a produção científica relacionada as questões étnico-raciais (raça, racismo); saúde mental da população negra e educação das relações étnico-raciais. A investigação foi efetuada por meio de busca eletrônica em publicações científicas indexadas. Citamos como exemplo, a base de dados da Biblioteca Virtual em Saúde (BVS) que envolve uma vasta produção científica alinhadas as nossas palavras-chave. Assim como a base de dados da Scientific Electronic Library Online (SCIELO). Realizamos ainda uma busca na Plataforma Sucupira que disponibiliza informações de Dissertações e Teses produzidas no Brasil. De modo geral, privilegiamos a análise de produções mais recentes (artigos, Dissertações e Teses). Isto é, a partir da última década, que tem como marco legal, importantes resoluções que envolveram a temática investigada (Resolução 68/237 - Conferência de Durban/ONU). Os dados coletados subsidiaram a elaboração de uma planilha que facilitou a sistematização das informações que mereceram interpretações.

1 O Conselho Nacional de Desenvolvimento Científico e Tecnológico (CNPq) no Brasil, classifica a Psicologia como sendo parte das Ciências Humanas. A Resolução $n^{\circ}$ 218/97 do Conselho Nacional de Saúde reconhece os psicólogos como profissionais da Saúde. 
Partindo de algumas reflexões de Jurema Werneck (2016) apreendemos que essa autora chama a atenção às reivindicações dos movimentos sociais negros, em especial do Movimento Negro e da população negra que tem lutado por qualidade e acesso ao sistema de saúde no país. Entretanto, "ainda, não foi suficiente para inserir no [sistema de saúde] mecanismos explícitos de superação das barreiras enfrentadas pela população negra no acesso à saúde, particularmente aquelas interpostas pelo racismo" (Werneck, 2016, p. 536, grifo nosso). Ainda, segundo Werneck (2016), “dessa perspectiva, 'racismo institucional' equivaleria a ações e políticas institucionais capazes de produzir e/ou manter a vulnerabilidade de indivíduos e grupos sociais vitimados pelo racismo" (Werneck, 2016, p. 543).

Silvio Almeida (2019) acrescenta a esse debate, enfatizando que "o racismo é uma forma sistemática de discriminação que tem a raça como fundamento, e que manifesta por meio de práticas (...) que culminaram em desvantagens ou privilégios para indivíduos, a depender do grupo social ao qual pertençam" (Almeida, 2019, p. 32). Neste sentido, compartilhamos das reflexões de Stuart Hall (2003) que "raça é uma construção política e social. É uma categoria discursiva em torno da qual se organiza um sistema de poder socioeconômico, de exploração e exclusão - ou seja, o racismo" (Hall, 2003, p. 69). Segundo Grada Kilomba (2019, p. 76), "é a combinação do preconceito e do poder que forma o racismo. E, nesse sentido, o racismo é a supremacia branca".

Nesta direção, Silvia Maeso (2019) assinala "que repensar o presente-futuro do antirracismo requer uma análise da supremacia branca entendida como relação de poder, uma análise que questione os contornos raciais, (pós)coloniais, do “(des)abrigo” político" (Maeso, 2019, p. 2060). As reflexões desses autores, permitem sustentar um olhar analítico e político para grupos racializados, com o propósito de descrever e interpretar a operação do racismo estrutural na produção e sustentação de desigualdades sociais, em especial no sistema de saúde, como enfatizam Luís Batista et al. (2013). Assim como refletir sobre estratégias para seu combate e sua superação. Ressaltamos assim, a importância da PNSIPN.

Entendemos que "o racismo é um determinante social em saúde que coloca a população negra em condições de vulnerabilidade frente ao processo de garantia das condições de saúde e vida dos usuários do SUS", como observado no documento Temático Saúde da População Negra (Ministério da Saúde, 2016, p. 8). Acrescentamos a esta discussão outros pressupostos focalizados no documento Política Nacional de Saúde Integral da População Negra: uma política para o SUS (Ministério da Saúde, 2017) que tem como indicadores, entre outros, "o reconhecimento do racismo, das desigualdades étnico-raciais e 
do racismo institucional como determinantes sociais das condições de saúde, com vistas à promoção da equidade em saúde” (Ministério da Saúde, 2017, p. 18).

A luta do Movimento Negro no Brail vem de longa data buscando o comprometimento do Estado no combate as iniquidades em saúde, que são resultados "de injustos processos socioeconômicos e culturais - em destaque, 0 vigente racismo - que corroboram com a morbimortalidade das populações negras brasileiras" (Ministério da Saúde, 2017, p. 7). Compreendemos que os modos de adoecer e morrer da população negra no Brasil refletem contextos de vulnerabilidade que são expressos em iniquidades em saúde.

Um dos grupos vulneráveis mais afetados pelo suicídio no Brasil são os jovens e sobretudo os jovens negros, devido principalmente ao preconceito e à discriminação racial e ao racismo estrutural, como pudemos observar por meio do relatório Óbitos por suicídio entre adolescentes e jovens negros 2012 a 2016 (Ministério da Saúde, 2018). Esse documento mostra que entre 2012 e 2018, "a proporção de suicídios entre negros aumentou em comparação às demais (cor/raça) subindo de 53,3\% em 2012 para 55,4\% em 2016 (Ministério da Saúde, 2018, p. 23).

Há continuidade e/ou rupturas às desigualdades em saúde que acometem à população negra que resultam de injustos processos sociais, culturais e econômicos, em especial na área da saúde, presentes na história do Brasil? Nesta direção, temos observado que diversos seguimentos na sociedade brasileira têm buscado medidas para combater o racismo institucional. Citamos como exemplo, a área da Psicologia, onde o enfrentamento ao racismo está regulamento na Psicologia brasileira desde o inicio da década de 2000 quando foi criado pelo Conselho Federal de Psicologia (CFP, 2002), a Resolução CFP $n^{\circ}$. 18/2002 que estabelece normas para atuação das psicólogas e dos psicólogos, em relação ao preconceito, à discriminação racial e ao combate ao racismo, determinando que todos os profissionais da Psicologia atuarão segundo os princípios éticos da profissão, contribuindo com o seu conhecimento para uma reflexão sobre o preconceito e para a eliminação do racismo.

Ressaltamos ainda, o contexto da pandemia, do novo coronavírus covid-19 que tem afetado as sociedades contemporâneas de modo global. A Organização Mundial de Saúde, veio a público, por meio de seu Diretor geral, Tedros Adhanom Ghebreyesus, mostrar grande preocupação com a pandemia. Assim como do impacto causado pela pandemia na saúde mental das pessoas, onde 0 isolamento social, o medo de contágio, a escassez de vacinas, e a perda de membros da família são agravados pelo sofrimento causado pela perda de renda e emprego. Os fatores apontados como extremamente preocupantes 
descrevem a vida da grande maioria das pessoas negras e pobres que vivem no Brasil. Esta constatação aponta para a urgência de compreender a saúde mental da população negra em contexto da covid-19.

Compreendemos que a luta contra a covid-19 exige uma leitura racial e social, como destacado por Márcia A. P. Santos et al. (2020):

Apesar desse contexto, o quesito raça/cor não foi elegível para análise de situação epidemiológica da Covid-19 nos primeiros boletins epidemiológicos (...). A incorporação do quesito raça/cor como categoria de análise (...) se deu após posicionamentos do GT Racismo e Saúde, da Coalizão Negra e da Sociedade Brasileira de Médicos de Família e Comunidade. (p. 228)

Ainda segundo Santos et al. (2020, p. 228), "a inclusão do quesito raça/cor nos formulários dos sistemas de informação em saúde é de competência das esferas de gestão do SUS (...), contendo informação desagregada por raça/cor passou a ser obrigatório. (...) Portaria n. 344 do Ministério da Saúde em 2017".

Para além da introdução, na primeira parte, apresentamos um breve histórico do campo da Psicologia e os estudos das relações étnico-raciais, ampliados pelo debate da área de Educação das relações étnico-raciais, antirracismo e saúde mental. Na segunda parte, tecemos algumas considerações sobre a Psicologia e suas práticas no campo da Saúde mental e relações étnico-raciais, para em seguida apresentarmos nossas considerações finais.

\section{A PSICOLOGIA E OS ESTUdoS dAS RELAÇõES ÉTNICO-RACIAIS}

Santos et al. (2012), ao discutirem sobre o pensamento psicológico brasileiro e relações étnico-raciais, destacam três momentos. 0 primeiro (do final do século XIX e início do século XX), "caracterizado pelo surgimento e consolidação de um modelo médico psicológico que culminou na Escola Nina Rodrigues, que atribui e investiga as características psicológicas dos [escravizados e exescravizados]" (Santos et al., 2012, p. 167, grifo nosso). Segundo esses autores, esta parte da população era considerada um "elemento perigoso", assim, precisaria de controle e sujeito à exclusão social, "O olhar científico sobre esse grupo social fornece os elementos necessários para a configuração do negro como sujeito psicológico e objeto da ciência (Santos et al., 2012, p. 167).

Alberto Ramos (1957) já nos alertará para o "problema do negro", do "negro como objeto de estudo", o autor desenvolveu estudos sobre o pensamento social brasileiro. Esse é o sentido, por exemplo, de passagens como a seguinte, do ensaio Patologia social do branco brasileiro, em que o autor distingue entre as categorias negro-vida e negro-tema. Há o tema do negro e há a vida do negro. "Como tema, o negro tem sido, entre nós, objeto de escalpelação perpe- 
trada por literatos (...). Como vida ou realidade efetiva, o negro vem assumindo o seu destino, vem se fazendo a si próprio, segundo lhe têm permitido as condições particulares das sociedades" (Ramos, 1957, p. 171).

O segundo momento tangencia o período (1930-1950) como assinalam, Santos, et al. (2012), e foi "caracterizado pela introdução da Psicologia no ensino superior e pelo debate sobre a construção sociocultural das diferenças com contribuições de "Raul Briquet, Arthur Ramos, Donald Pierson, Virgínia Leone Bicudo, Aniela Ginsberg e Dante Moreira Leite" (Santos et al., 2012, p. 167). Período de crítica e de desconstrução e rompimento do determinismo biológico acerca dos estudos de raça no campo da Psicologia Social no Brasil.

0 terceiro momento destacado por esses autores se refere a década de 1990 e as seguintes. Desse modo, notamos uma fase inicial, caracterizada por "estudos sobre branqueamento e branquitude, com Jurandir Freire Costa, Iray Carone, Maria Aparecida Bento e Edith Piza" (Santos et al., 2012, p. 168). Nesta direção, Lourenço Cardoso (2008) chama a atenção para a emergência do debate sobre a branquitude enquanto tema nas pesquisas sobre relações raciais no Brasil. Segundo esse autor:

$\mathrm{Na}$ ideologia do branqueamento, o branco não é "invisibilizado", pelo contrário, seria o ideal desejado de uma nação. Na medida em que os discursos neo-freyrianos invisibilizam a raça propondo sua integração na identidade nacional, a militância negra procura "visibilizar" o branco propondo a identidade negra. A ideologia do branqueamento, assim, vai perdendo espaço para se pronunciar. (Cardoso, 2008, p. 208)

Cardoso (2008), na trilha de diversos autores que abordam o conceito de branquitude: Alberto Guerreiro Ramos, Frantz Fanon, César Rossatto, Verônica Gesser, Maria Aparecida Bento, Lia Schucman, defende a importância da discussão acerca da branquitude para luta antirracista na área da educação, colaborando com a supressão das hierarquias raciais (Rossato e Gesser, 2001). Segundo Lia Schucman (2012, p. 7):

A branquitude é entendida (...) como uma construção sócio-histórica produzida pela ideia falaciosa de superioridade racial branca, e que resulta, nas sociedades estruturadas pelo racismo, em uma posição em que os sujeitos identificados como brancos adquirem privilégios simbólicos e materiais em relação aos nãos brancos. (Schucman, 2012, p. 7)

Adelina Nunes (2020, p. 8) acrescenta a esta discussão e assinala que "o perfil racial, majoritariamente branco, das e dos docentes do ensino superior emerge como um desafio na inclusão de um projeto antirracista para a educação". Cenário que se faz presente em diversas universidades, como aponta o estudo de Luiz Mello e Ubiratan Resende (2019), onde esses autores mostram a ausência 
de docentes, em particular, negros e de povos indígenas. Denise Carreira (2018) chama a atenção para a "desconstrução da branquitude como lugar de manutenção de privilégios materiais, subjetivos e simbólicos na sociedade e base de sustentação do racismo" (Carreira, 2018, p. 128). As reflexões destes autores nos levam a refletir acerca da implementação das políticas públicas educacionais no campo da Educação no país.

Citamos como exemplo as políticas de ação afirmativa (Lei $n^{\circ}$. 12.711/2012), a Lei $\mathrm{n}^{\circ}$. 12.990/2014 (reserva 20\% das vagas de concursos públicos federais para candidatas/ os negras/os), a obrigatoriedade de se incluir nos currículos oficiais dos sistema de ensino no Brasil, as Leis $n^{\circ}$. 10.639/2003 (História e Cultura Afro-brasileira e Africana); Lei $n^{\circ}$. 11.645/2008 (História e Cultura Afrobrasileir e Indígena) e das DCNERER.

Segundo Marcos Silva e Silvia Ribeiro (2019):

Dessa perspectiva, as leis, bem como suas práticas, constituem elementos significativos de estudos da realidade social, política e educacional. Exemplarmente as Leis $n^{\circ}$. 10.639/03 e $n^{\circ} .11 .645 / 08$ (...), refletem a tensão presente na história das políticas educacionais do país, pois de um lado há políticas que visam à permanência do racismo estrutural que se revela pela invisibilidade da raça e pelo mito da democracia e, de outro, políticas frutos de lutas sociais que buscam romper com as primeiras. (Silva e Ribeiro, 2019, p. 79)

Compreendemos que a educação das relações étnico-raciais no sistema educacional, em especial no ensino superior, visa a produção de conhecimentos "que eduquem cidadãos quanto à pluralidade étnico-racial, tornando-os capazes de interagir e de negociar objetivos comuns que garantam, a todos, respeito aos direitos legais e valorização de identidade, na busca da consolidação da democracia brasileira" (Conselho Nacional de Educação, 2004, p. 31). Para tal, é necessário para além da inclusão da população racializadas (negros, povos indígenas) na universidade, uma (re)educação dos discursos, bem como reconhecimento e valorização da história e cultura dos afro-brasileiros e dos povos indígenas. "Por exemplo: em Medicina, entre outras questões, estudo da anemia falciforme, da problemática da pressão alta" (Conselho Nacional de Educação, 2004, p. 24). Na trilha de Aparecida Ferreira (2012) acreditamos que trazer 0 debate da educação antirracista corrobora com o campo da Psicologia e Saúde mental, porque "nomeia assuntos de raça e de justiça social, de igualdade racial/étnica, assuntos relacionados a poder, a exclusão" (Ferreira, 2012, p. 278). 


\section{Psicologia e Educação Antirracistas: um campo em construção}

Segundo Ramón Grosfoguel (2016):

O racismo (...) epistêmico é um dos problemas mais importantes do mundo contemporâneo. 0 privilégio epistêmico dos homens ocidentais sobre o conhecimento produzido por outros corpos políticos e geopolíticas do conhecimento tem gerado não somente injustiça cognitiva, senão que tem sido um dos mecanismos usados para privilegiar projetos imperiais/coloniais/patriarcais no mundo. (...) Essa legitimidade e esse monopólio do conhecimento dos homens ocidentais tem gerado estruturas e instituições que produzem o racismo/sexismo epistêmico, desqualificando outros conhecimentos e outras vozes críticas frente aos projetos imperiais/coloniais/patriarcais que regem o sistema-mundo. (Grosfoguel, 2016. p. 25)

Vale ressaltar que a educação das relações étnico-raciais, em especial no currículo universitário, com raras exceções apresentam-se "como um modelo eurocentrado" (Araújo e Silva, 2020, p. 346). Paulo Silva et al. (2018, p. 22) assinalam que a obrigatoriedade da inserção da história e cultura afro-brasileira e africana nas instituições educacionais "provoca o questionamento sobre a seletividade dos currículos (...) ao discutir que eles não transmitem simplesmente o conhecimento acumulado pela humanidade: eles são seletivos e omitem e/ou distorcem a História e Cultura dos africanos e dos negros brasileiros".

Apreendemos que esta discussão se faz presente no campo da Psicologia. Por exemplo, Diogo Pereira e Cristiane Silva (2018) indicaram "a necessidade de uma adequação curricular às normas vigentes, bem como a necessidade de discutir a formação em psicologia e a transversalidade no currículo (...) para a diversidade" (Pereira e Silva, 2018, p. 162). Por sua vez, Sônia Sampaio (2010) assinala que com raras exceções os cursos de Psicologia são "restritos por currículos que ainda passam ao largo da realidade socioeducacional brasileira" (Sampaio, 2010, p. 96). Nessa mesma direção, Alessandro Santos e Lia Schucman $(2015$, p. 137) chamam a atenção para que no âmbito dos cursos de pósgradução em Psicologia, estimulem-se "a produção de mais conhecimento sobre: a história do pensamento psicológico brasileiro na compreensão das relações raciais (Santos e Schucman, 2015, p. 137).

Bianca Suleiman (2014, p. 371) questiona: "como os cursos e licenciaturas de Psicologia vêm trabalhando com o racismo e as relações étnico-raciais no seu currículo?" Para essa autora, "a Psicologia tem muito a contribuir no processo de formação de professores ao evidenciar como se dá a constituição do sujeito na relação com a cultura, desnaturalizando preconceitos e estereótipos sobre 
as relações sociais e étnico-raciais do país" (Suleiman, 2014, p. 369). Compartilhamos das reflexões desses autores sobre a necessidade de maior engajamento da comunidade academica com vista a uma educação antirracista visando promover um maior conhecimento, reconhecimento e respeito pela cultura, história da população afrodescendentes, inclusive por meio de pesquisas e educação, em especial na formação dos psicólogos.

Nilma Gomes (2011) acrescenta a essa discussão assinalando que a efetivação dessas políticas públicas educacionais, "dependerá da necessária mobilização da sociedade civil a fim de que o direito à diversidade étnico-racial seja garantido nas escolas, nos currículos, nos projetos político-pedagógicos, na formação de professores, nas políticas educacionais" (Gomes, 2011, p. 116).

$\mathrm{Na}$ revisão de literatura, acerca da produção acadêmica sobre o campo da Psicologia e os estudos das relações étnico-raciais, localizamos outros estudos que ampliam este debate, por exemplo, Edna Martins et al. (2013) analisaram artigos de periódicos científicos brasileiros de Psicologia, publicados entre 2000 e 2009. Por uma lado, a análise desse autores mostra uma produção que de modo geral enfatizaram, "a violência psicológica do preconceito e do racismo; o legado social do branqueamento e seus efeitos psicossociais (...); e o monitoramento dos efeitos das políticas e dos programas de promoção da igualdade étnico-racial" (Martins et al., 2013, p. 118). Por outro, esses autores assinalam que o campo dos estudos das relações étnico-raciais, "têm sido objeto de investigação da psicologia, notadamente da psicologia social, e que a noção de raça aos poucos vem sendo incorporada pelos(as) pesquisadores(as) desse campo como categoria de análise" (Martins et al., 2013, p. 118).

Outros estudos do campo da Psicologia Social ilustram esse panorama. Citamos como exemplo alguns trabalhos que especificam os aspectos da educação por níveis de ensino (Educação Infantil, Educação Básica, Educação Superior), como pudemos encontrar nos trabalhos de Edmar Rocha e Fúlvia Rosemberg (2007), Antônio Ferreira (2010), Elcimar Pereira (2014), Marta Silva (2014), Marcos Silva (2016). Assim como de produções que discutem relatos de imigrantes africanos, sobre preconceitos na cidade de São Paulo, por meio do trabalho de Márcio Farias (2015).

Além do debate acerca da corporeidade negra e tensão regulação-emancipação social (corpo negro regulado e o corpo negro emancipado). Citamos como exemplo o estudo de Ivani Oliveira (2019). Compreendemos que a Psicologia por meio desses estudos se alinha a desconstrução do mito da democracia racial, bem como das desigualdades sociais e educacionais, que são atribuídas à herança do passado escravista, à política de branqueamento da passagem do 
século XIX para o XX, à histórica condescendência das elites brasileiras com desigualdades sociais e ao racismo estrutural, mas ainda falta muito a realizar.

\section{Psicologia, Saúde Mental e Racismo: pontos para reflexão}

Nesta subseção, apresentamos uma revisão sistemática sobre estudos que discutem o racismo e a saúde mental da população negra na sociedade brasileira, de acordo como o método proposto já evidenciado neste texto (BVS, SciELO; Plataforma Sucupira). Utilizando os descritores Psicologia; saúde mental; negros(as), localizamos produções que apontaram algumas tendências no que tangencia, a saber: a Reforma Psiquiátrica; a violência de gênero; o atendimento psicoterapêutico (cor/raça); a produção de conhecimento; a migração, coleta de dados étnico-raciais (cor/raça).

A primeira tendência incluiu os estudos que lançaram um olhar sobre o tema da saúde mental da população negra e a Reforma Psiquiátrica (Lei $\mathrm{n}^{\circ}$. 10.216/2001). Essa Lei dispõe sobre a proteção e os direitos das pessoas portadoras de transtornos mentais e redireciona o modelo assistencial em saúde mental. Marcos Ignácio e Ruben de Mattos (2019) apontam algumas questões relacionadas. Isto é, "a falta de sensibilidade étnico-racial na Rede de Atenção Psicossocial e a necessidade de acolhimento do sofrimento psíquico atravessado pelo racismo" (Ignácio e Mattos, 2019, p. 66).

Na segunda tendência, observamos o estudo de Tafnes Martins et al. (2020) que avaliaram, "o efeito das microagressões raciais de gênero na saúde mental de mulheres negras (...). Os resultados indicaram que a alta frequência de microagressões raciais de gênero prediz piores níveis de saúde mental e autoestima" (Martins et al., 2020, p. 2793). Nesta direção, "Em 2018, 68\% das mulheres assassinadas no Brasil eram negras", conforme observado por meio do estudo Atlas da Violência, do ano de 2020, realizado pelo Instituto de Pesquisa Econômica Aplicada (Ipea, 2020, p. 37).

$\mathrm{Na}$ terceira tendência, estão os estudos que destacam $\mathrm{o}$ atendimento psicoterapêutico. Marizete Damasceno e Valeska Zanello (2019) chamam a atenção sobre as "narrativas de pessoas negras atendidas por psicoterapeutas brancos/as, sobre suas vivências de racismo no cotidiano e sobre como se deu a escuta na terapia em díade birracial" (Damasceno e Zanello, p. 1). Essas autoras destacam, a transferência inter-racial no processo terapêutico, e a falta de formação do psicoterapeuta para atender clientes negros.

Por sua vez, Jeane Tavares e Sayuri Kuratani (2019) reforçam as considerações anteriores e mostram a invisibilidade da produção sistemática de conhecimentos, métodos ou estratégias para o manejo clínico das repercussões do racismo sobre a saúde mental da população negra. Ainda, segundo esses 
autores, "esta é uma lacuna teórica e prática relevante, pois, quando o terapeuta não reconhece o racismo como produtor de iniquidades sociais (...), contribui para aumento de sofrimento psíquico de seu paciente negro e para a manutenção das desigualdades raciais" (Tavares e Kuratani, 2019, p. 1).

$\mathrm{Na}$ quarta tendência, observamos estudos que problematizam o debate acerca da educação das relações étnico-raciais e a descolonização dos currículos na formação dos psicólogos (Alves et al., 2015; Veiga, 2019). Lucas Veiga (2019), por exemplo, destaca que "o cuidado da saúde mental da população negra brasileira não pode se dar sem um resgate epistemológico das produções negras sobre o tema" (Veiga, 2019, p. 244). Segundo Gomes (2012), “a descolonização do currículo implica conflito, confronto, negociações e produz algo novo (Gomes, 2012, p. 107).

$\mathrm{Na}$ quinta tendência, Alexandre Branco Pereira (2018) apresenta reflexões etnográficas por meio de um trabalho de campo realizado em serviço de assistência em saúde mental para refugiados na cidade de São Paulo, onde "a característica fenotípica parece ser determinante para a leitura de alguém enquanto refugiado (...), só o refugiado branco aparece aos olhos dos serviços". O refugiado negro tende a ficar na (in)visibilidade, com desigualdade de tratamento (Branco Pereira, 2018, p. 91).

A sexta tendência apresenta estudos que analisaram o perfil de moradores de hospitais psiquiátricos do Estado de São Paulo, considerando as categorias (cor/raça). A análise do estudo de Sônia Barros et al. (2014) mostra que 38,36\% da população residente de hospitais psiquiátricos era negra, na faixa etária entre 35 a 49 anos de idade. Com relação aos dados clínicos. Esses autores chamam a atenção para a "proporção de esquizofrenia, transtorno esquizotípicos e delirantes", entre homens negros e mulheres negras (Barros et al., 2014, p. 1244). Compartilhamos das reflexões desses autores que é crucial discutir a influência do racismo e suas práticas no campo da Saúde e Saúde mental, incluindo a psicoterapia e tratamentos hospitalar no que tangencia a saúde mental da população negra no país.

\section{PSICOLOGIA, SABERES E PRÁTICAS: SAÚDE MENTAL E RELAÇÕES ÉTNICO-RACIAIS}

Esta parte comporta algumas discussões, por meio de autores que apresentam contribuições para o campo dos estudos de relações étnico-raciais e da prática de Psicologia no Brasil. "Os textos apontam para novas possibilidades epistemológicas para a condução da prática clínica da Psicologia e também para profícuos diálogos entre os estudos de Psicologia, Antropologia e Estudos Afrodiaspóricos", como destacou Cintia Vianna et al. (2020, p. 2). Nesta 
direção, vale destacar o debate proposto por alguns autores que dialogaram com os saberes e práticas da Psicologia e da Saúde mental.

Deivison Faustino e Maria Oliveira (2020) destacaram as contribuições de Frantz Fanon para o debate da saúde mental nas sociedades contemporâneas no que se refere ao "conjunto de (...) reflexões sociológicas, políticas e filosóficas, elementos esses pouco explorados na literatura especializada em seu pensamento" (Faustino e Oliveira, 2020, p. 12). Rachel Passos (2020) acrescenta a esse debate destacando que devemos reconhecer o apagamento do pensamento de Frantz Fanon, "como consequência do mito da democracia racial que se materializou não só pelo viés político, teórico, ideológico como também na própria constituição da clínica ampliada, além da psiquiatrização e medicalização das subjetividades negras" (Passos, 2020, p. 81).

Alicerçados pela discussão da obra Pele negra, máscaras brancas, de Frantz Fanon (2008), Faustino e Oliveira (2020) apresentam "duas categorias encontradas, a saber: sociogenia e a alienação colonial, para, em seguida, apresentar algumas provocações mais gerais para o campo da Saúde Mental" (Faustino e Oliveira, 2020, p. 13). Compreendemos o quanto o processo de adoecimento da população negra e do adoecimento psíquico é produto do colonialismo (Passos, 2020).

Alessandro Campos (2020) e Maria Lucia Silva (2020) enfatizam o debate de Lélia Gonzalez, a latinidade como um grande desafio, a partir da busca de um "território existencial atravessado por paradoxos, dicotomias, ambiguidades e confrontos" (Silva, 2020, p. 4). "O campo de estudos afro-latino-americanos implica atravessamentos da [escravização], a forma de interpretação das relações raciais, as desigualdades raciais e a forma de organização política por todo esse contingente geográfico" (Campos, 2020, p. 27, grifo nosso).

Clélia Prestes (2020) reforça que "a luta contra o racismo é estrutural e identitária, é pela democracia e pelo direito de se ter vida psíquica livre dos efeitos traumáticos da dominação" (Costa, 2020, p. 78). Emiliano David (2020) considera que "a descolonização das práticas de cuidado e a inclusão das teorias e dos saberes afro-diaspóricos podem ampliar a potência de um agir em saúde" (David, 2020, p. 108). Desse modo contribuindo para a "promoção da equidade racial, e para a desinstitucionalização do racismo" (David, 2020, p108).

Jeane Tavares et al., (2020) enfatizam sobre o modo que campo da saúde mental teve seu início. 0 campo foi demarcado "por um modelo eugenista que se atualiza em diferentes momentos históricos, contribuindo para a manutenção de uma hierarquia racial (...), destacando o racismo como 
produtor de sofrimento psíquico, tema negligenciado até hoje", como assinala Maria Lúcia Silva (2020, p. 5). Isto é, "a implementação de políticas públicas direcionadas à saúde da população negra brasileira tem sido insuficiente e isto contribui para a manutenção da hierarquia racial estabelecida pelo colonialismo" (Tavares, 2020, p. 138).

Vale destacar a contribuição de Maria Lúcia Silva e Maria Ondina Peruzzo (2020), que deram ênfase a comemoração de 10 anos de existência da Articulação de Nacional de Psicólogas/os Negras/os e Pesquisadoras/es Negras/os. As autoras chamam a atenção para a Campanha \#SaúdeMentalDaPopulaçãoNegralmporta. Essa Campanha de forma coletiva possibilitou "a ampliação de alianças e a reflexão sobre o tema (...); a construção de um terreno fértil para que avancemos na edificação de uma sociedade onde a diferença não se materialize em desigualdade e de como 0 fazer coletivo é uma forma de produzir saúde" (Silva e Peruzzo, 2020, p. 152).

Estas autoras, ainda tecem considerações sobre os protestos contra o combate ao racismo (globalblack lives matter, "vidas negras importam"). Assim, como todos nós, solidarizaram-se com homens e mulheres negras, adultos e jovens negros que têm sido brutalmente assinados por agentes de segurança pública nas sociedades contemporâneas. "Dias antes do assassinato de George Floyd nos USA, o adolescente João Pedro Matos Pinto foi morto por disparos realizados durante uma operação policial no Complexo do Salgueiro, em São Gonçalo - RJ, em 18 de maio de 2020" (Silva e Peruzzo, 2020, p. 152).

De acordo com o Anuário Brasileiro de Segurança Pública, apreendemos com Samira Bueno et al. (2020) que a morte de George Floyd, em maio de 2020, "reacendeu o debate sobre letalidade policial e racismo nas instituições policiais não só nos Estados Unidos, mas também no mundo" (Bueno et al., 2020, p. 89). No Brasil, "somam-se às recentes vítimas de intervenções policiais com resultado morte no país, cujo perfil, majoritariamente formado por jovens, negros e do sexo masculino, deve ser considerado enquanto evidência na formulação de políticas públicas de segurança e de controle do uso da força." (Bueno et al., 2020, p. 89). Nesta direção, Jaime Alves (2011) acrescenta a esse debate:

Proponho entendermos a violência estatal - em suas múltiplas faces como uma categoria "necropolítica" (MBEMBE 2003) pela qual o Estado exerce o seu poder de soberania. Todavia, entendo como violência estatal não apenas as já banalizadas práticas policiais de extermínio e massacre nas favelas, mas também a cumplicidade e a displicência estatal com a violência homicida, a violência cotidiana expressa na segregação espacial, 
a negação sistemática dos direitos de cidadania, as mortes evitáveis nas filas dos hospitais públicos. (Alves, 2011, p p. 109-110)

Compreendemos que a violência também se impõe na agenda da saúde mental de diversas maneiras. É crucial e urgente que a Psicologia, possa ampliar cada vez mais o seu olhar para o combate e eliminação de formas de opressão e violência.

\section{CONSIDERAÇÕES FINAIS}

O estudo permitiu examinar a relação entre fatores contextuais do campo da Psicologia envolvendo Saúde mental e as questões étnico-raciais, notadamente raça, racismo, antirracismo, complementado pelo debate da Educação das relações étnico-raciais. A revisão de literatura proporcionou colocar em primeiro avanços e desafios no que tange ao campo investigado, em particular, a população negra nas sociedades contemporâneas, em especial, a sociedade brasileira.

Por um lado, apreendemos que o enfrentamento ao racismo faz parte das diretrizes que regem a Psicologia brasileira, por meio de normas para atuação dos psicólogos, com base em diversas normativas nacionais e internacionais. Assim como observamos que o campo da Psicologia da perspectiva étnico-racial faz parte do pensamento psicológico brasileiro, desde o final do século XIX, onde foi possível notar a construção de uma linha no tempo configurando uma descontinuidade e a configuração de novas práticas e saberes em Psicologia. Por outro, observamos um chamamento para que se coloquem em prática a Educação das relações étnico-raciais como componente curricular obrigatório nos cursos de formação de Psicologia para que esses possam contemplar uma reflexão crítica acerca do debate de raça, racismo, antirracismo nos planos políticos-pedagógicos e curriculares. Embora as políticas públicas educacionais já estejam em vigor no país, em especial, as Leis $n^{\circ}$. 10.639/2003, $n^{\circ}$. $11.645 / 2008$, e suas Diretrizes, conquista do Movimento Negro, em algumas universidades demora para acontecer.

No que se refere ao debate sobre Saúde mental e racismo, notamos que literatura acadêmica tem discutido a temática, em especial pela ótica de psicólogos negros e negras, que tem lançado um olhar sobre o tema da saúde mental da população negra, por meio de diferentes aspectos: a reforma psiquiátrica; a violência de gênero; 0 atendimento psicológico (escuta terapêutica, narrativas de pessoas negras atendidas por psicoterapeutas brancos); a influência do racismo em nível de saúde mental. Conclui-se que devemos investir e insistir em culturas curriculares e epistemológicas no campo da Psicologia e suas práticas clínicas que promovam avanços em debates sobre 
os efeitos do racismo na saúde mental da população negra, visando a promoção em saúde, equidade racial e ao combate ao racismo.

\#SaúdeMentalDaPopulaçãoNegralmporta!

\section{FINANCIAMENTO}

European Research Council(ERC-2016-COG-725402)

\section{REFERÊNCIAS}

Almeida, Silvio L. (2019). Racismo estrutural. Sueli Carneiro; Polém.

Alves, Jaime A. (2011). Topografia da violência: Necropoder e Governamentalidade Espacial em São Paulo. Revista Do Departamento De Geografia, 22, 108-134. https: / / doi.org/10.7154/RDG.2011.0022.0006

Alves, Míriam C.; Jesus, Jayro P., \& Scholz, Danielle (2015). Paradigma da afrocentricidade e uma nova concepção de humanidade em saúde coletiva: reflexões sobre a relação entre saúde mental e racismo. Saúde em Debate, 39(106), 869880. https://doi.org/10.1590/0103-1104201510600030025

Araújo, Danielle P. \& Silva, Marcos A. B. (2020). O ensino da história e cultua afrobrasileira e indígena no currículo dos cursos de pedagogia de duas instituições de ensino superior. @rquivo Brasileiro De Educação, 8(17), 322-351. https://doi.org/10.5752/ P. 2318-7344.2020v8n17p322-351

Barros, Sonia; Batista Luis E.; Dellosi Mirsa E \& Escuder Maria M. L. (2014). Censo psicossocial dos moradores em hospitais psiquiátricos do estado de São Paulo: um olhar sob a perspectiva racial. Saúde e Sociedade, 23(4), 1235-

1247. https://doi.org/10.1590/S0104-12902014000400010

Batista, Luís E.; Monteiro, Rosana B. \& Medeiros, Rogério A. (2013). Iniquidades raciais e saúde: o ciclo da política de saúde da população negra. Saúde debate [Internet], 37(99), 681-690. https://doi.org/10.1590/S0103-11042013000400016.

Branco Pereira, Alexandre. (2018). O refúgio do trauma. Notas etnográficas sobre trauma, racismo e temporalidades do sofrimento em um serviço de saúde mental para refugiados. REMHU: Revista Interdisciplinar da Mobilidade Humana, 26(53), 79 97. https://doi.org/10.1590/1980-85852503880005306

Bueno, Samira; Pacheco, Dennis \& Nascimento, Talita. (2020). O crescimento das mortes decorrentes de intervenções policiais no Brasil. In Anuário Brasileiro de Segurança Pública. Fórum de Segurança Pública (pp. 86-94). https: / / forumseguranca.org.br/wp-content/uploads/2020/10/anuario-14-2020-v1interativo.pdf

Campos, Alessandro O. (2020). A Psicologia e o racismo estrutural na atualidade Latino-Americana. Revista Da Associação Brasileira De Pesquisadores/As Negros/As (ABPN), 12(Ed. Especi), 27-51. https://www.abpnrevista.org.br/index.php/site/article/view/1111

Cardoso, Lourenço. (2008). O branco "invisível": um estudo sobre a emergência da branquitude nas pesquisas sobre as relações raciais no Brasil (Período: 1957- 2007). 
Dissertação de Mestrado inédita, Universidade de Coimbra. https://dlc.library.columbia.edu/catalog/ldpd:504811/bytestreams/content/conten t?filename=LOUREN\%C3\%870+DA+CONCEI\%C3\%87\%C3\%830+CARDOSO.pdf

Carreira, Denise. (2018). O lugar dos sujeitos brancos na luta antirracista. SUR 15(28), 127-137. https://sur.conectas.org/wp-content/uploads/2019/05/sur-28-portuguesdenise-carreira.pdf

Conselho Federal de Psicologia (2002). Resolução CFP $n^{\circ}$. 18/2002. Conselho Federal de Psicologia. Brasília-DF, 19 de dezembro de 2002. https://site.cf p. org.br/tag/resolucao-cfp-18-2002/

Conselho Nacional de Educação (2004). Resolução $n^{\circ}$. 1. Diário Oficial da União. Brasília, 22 jun. 2004, Seção 1, p. 11.

http://portal.mec.gov.br/cne/arquivos/pdf/res012004.pdf

Costa, Eliane S. (2020). Vínculos, Grupos e Redes em Prol da Vida ou na Pactuação Racista para a Produção de Morte. Revista Da Associação Brasileira De Pesquisadores/As Negros/As (ABPN), 12(Ed. Especi), 78-107. https://www.abpnrevista.org.br/index.php/site/article/view/1117

Damasceno, Marizete G. \& Zanello, Valeska. (2019). Psicoterapia, raça e racismo no contexto brasileiro: experiências e percepções de mulheres negras. Psicologia Em Estudo, 24. https:// doi.org/10.4025/psicolestud.v24i0.42738

David, Emiliano C. (2020). Relações Raciais, Uma Questão Antimanicomial. Revista Da associação Brasileira De Pesquisadores/As Negros/As (ABPN), 12(Ed. Especi), 108137. https://www.abpnrevista.org.br/index.php/site/article/view/1116

Fanon, Frantz (2008). Pele negra, máscaras brancas (Tradução de Renato da Silveira). EDUFBA.

Farias, Márcio (2015). Relatos de imigrantes africanos sobre preconceito na cidade de São Paulo. Dissertação de Mestrado inédita, Pontifícia Universidade Católica de São Paulo. https://sapientia.pucs p. br/handle/handle/17125

Faustino, Deivison M. (2017). A universalização dos direitos e a promoção da equidade: o caso da saúde da população negra. Ciência \& Saúde Coletiva, 22(12), 3831 3840. https: / / doi.org/10.1590/1413-812320172212.25292017

Faustino, Deivison M. \& Oliveira, Maria C. (2020). Frantz Fanon e as máscaras brancas da saúde mental: subsídios para uma abordagem psicossocial. Revista Da Associação Brasileira De Pesquisadores/As Negros/As (ABPN), 12(Ed. Especi), 6-26. https://www.abpnrevista.org.br/index.php/site/article/view/1110

Ferreira, Antônio H. (2010). Discursos étnico-raciais proferidos por candidatos/as a programa de ação afirmativa. Tese de Doutorado inédita, Pontifícia Universidade Católica de São Paulo. https://sapientia.pucs p. br/handle/handle/16903

Ferreira, Aparecida J. (2012). Educação antirracista e práticas em sala de aula: uma questão de formação de professores. Revista De Educação Pública, 21(46), 275-288. https://doi.org/10.29286/re p. v21i46.40

Gomes, Nilma L. (2011). Diversidade étnico-racial, inclusão e equidade na educação brasileira: desafios, políticas e práticas, Revista Brasileira de Política e Administração da Educação, 27(1), p. 109-121. https://doi.org/10.21573/vol27n12011.19971 
Gomes, Nilma L. (2012). Desigualdades e diversidade na educação. Educação \& Sociedade, 33(120), 687-693. https://doi.org/10.1590/S0101-73302012000300002

Grosfoguel, Ramón (2016). A estrutura do conhecimento nas universidades ocidentalizadas: racismo/sexismo epistêmico e os quatro genocídios/epistemicídios do longo século XVI. Sociedade e Estado, 31(1), 25-49. https://dx.doi.org/10.1590/S0102-69922016000100003

Hall, Stuart (2003). Da Diáspora: identidade e mediações culturais. UFMG.

Ignácio, Marcos V. M. \& Mattos, Ruben A. (2019). O Grupo de Trabalho Racismo e Saúde Mental do Ministério da Saúde: a saúde mental da população negra como questão. Saúde em Debate, 43(spe8), 66-78. Epub August 07, 2020. https://doi.org/10.1590/0103-11042019s805

Instituto de Pesquisa Econômica Aplicada- Ipea. (2020). Atlas da Violência 2020. https://dx.doi.org/10.38116/riatlasdaviolencia2020

Kilomba, Grada. (2019). Memórias da plantação: episódios de racismo cotidiano. Cobogó.

Lei n. 10.216/2001(2001, 6 de abril). Presidência da República. Diário Oficial da União, Brasília. http://www.planalto.gov.br/ccivil_03/leis/leis_2001//10216.htm

Lei ${ }^{\circ}$. 10.639/03 (2003, 10 de janeiro). Presidência da República. Diário Oficial da União, Brasília. http://www.planalto.gov.br/ccivil_03/LEIS/2003/L10.639.htm

Lei $n^{\circ}$. 11.645/08 (2008, 11 de março). Presidência da República. Diário Oficial da União, Brasília. http://www.planalto.gov.br/ccivil_03/_Ato20072010/2008/Lei/L11645.htm

Lei 12.711/2012 (2012). Presidência da República. Diário Oficial da União, Brasília, 30 de agosto de 2012. http://www.planalto.gov.br/ccivil_03/_ato20112014/2012/lei/l12711.htm

Lei $n^{\circ}$. 12.990/2014. (2014, 9 de junho). Presidência da República. Diário Oficial da União, Brasília. http://www.planalto.gov.br/ccivil_03/_ato2011-

2014/2014/lei/112990.htm

Maeso, Silvia R. (2019). O Estado de negação e o presente-futuro do antirracismo: Discursos oficiais sobre racismo, 'multirracialidade' e pobreza em Portugal (19852016). Revista Direito e Práxis, 10(3), 2033-2067. https://dx.doi.org/10.1590/21798966/2019/43883

Martins, Edna; Santos, Alessandro O. \& Colosso, Marina. (2013). Relações étnico-raciais e psicologia: publicações em periódicos da SciELO e Lilacs. Psicologia: teoria e prática, 15(3), 118-133.

http://pepsic.bvsalud.org/scielo.php?script=sci_arttext\&pid=S1516$36872013000300009 \& \operatorname{lng}=$ pt\&tlng=pt.

Martins, Tafnes V.; Lima, Tiago J. S. \& Santos, Walberto S. (2020). O efeito das microagressões raciais de gênero na saúde mental de mulheres negras. Ciência \& Saúde Coletiva, 25(7), 2793-2802. https://dx.doi.org/10.1590/141381232020257.29182018

Mello, Luiz \& Resende, Ubiratan P. (2019). Concursos públicos para docentes de universidades federais na perspectiva da Lei 12.990/2014: desafios à reserva de 
vagas para candidatas/os negras/os. Soc. estado., 34(1), 161-184. https://doi.org/10.1590/s0102-6992-201934010007

Ministério da Saúde. (2009). Portaria $n^{\circ}$. 992. Ministério da Saúde. Institui a Política Nacional de Saúde Integral da População Negra. Diário Oficial da União, Brasília. https://bvsms.saude.gov.br/bvs/saudelegis/gm/2009/prt0992_13_05_2009.html

Ministério da Saúde. (2016). Temático Saúde da População Negra. Ministério da Saúde. Secretaria de Gestão Estratégica e Participativa. Departamento de Articulação Interfederativa.

https://bvsms.saude.gov.br/bvs/publicacoes/tematico_saude_populacao_negra_v._. $\underline{\text { 7.pdf }}$

Ministério da Saúde (2017). Política Nacional de Saúde Integral da População Negra: uma política para o SUS. Ministério da Saúde, Secretaria de Gestão Estratégica e Participativa, Departamento de Apoio à Gestão Participativa. Ministério da Saúde. https://bvsms.saude.gov.br/bvs/publicacoes/politica_nacional_saude_populacao_ne gra_3d.pdf

Ministério da Saúde. (2018). Óbitos por suicídio entre adolescentes e jovens negros 2012 a 2016. Ministério da Saúde.

http://bvsms.saude.gov.br/bvs/publicacoes/obitos_suicidio_adolescentes_negros_20 12_2016.pdf

Nunes, Adelina M. B. (2020). A Branquitude e o Ensino Superior: reflexos e desafios na docência. Dissertação de Mestrado inédita, Universidade Federal de Ouro Preto. https: / / 1library.org/title/a-branquitude-ensino-superior-reflexos-desafios-nadocencia

Oliveira, Ivani F. (2019). Versões de mulheres negras sobre a transição capilar: um estudo sobre processos de descolonização estética e subjetiva. Dissertação de Mestrado inédita, Pontifícia Universidade Católica de São Paulo.

https://sapientia.pucs p. br/handle/handle/22176

Passos, Rachel G. (2020). "Crimes da Paz": as expressões do racismo na saúde mental da população negra. In: Patrícia C. Magno \& Rachel G. Passos (Eds.), Direitos humanos, saúde mental e racismo: diálogos à luz do pensamento de Frantz Fanon (pp. 72-83). Defensoria Pública do Estado do Rio de Janeiro.

Pereira, Diogo F. \& Silva, Cristiane M. (2018). Ensino de Psicologia e as discussões étnico-raciais. Revista UNIABEU, 11(28), 162-173. https://revista.uniabeu.edu.br/index.php/RU/article/view/2978

Pereira, Elcimar Dias (2014). Programa de ação afirmativa do Instituto Rio Branco: discursos de diplomatas e candidatos/as à diplomacia. Tese de Doutorado inédita, Pontifícia Universidade Católica de São Paulo. https://sapientia.pucs p. br/handle/handle/17079

Prestes, Clélia R.S. (2020). Não sou eu co campo psi? Vozes de Juliano Moreira e outras figuras negras. Revista Da Associação Brasileira De Pesquisadores/As Negros/As (ABPN), 12(Ed. Especi), 52-77. https://www.abpnrevista.org.br/index.php/site/article/view/1112

Ramos, Alberto G. (1957). Introdução crítica à sociologia brasileira. UFRJ. 
Rocha, Edmar J. \& Rosemberg Fúlvia (2007). Autodeclaração de cor e/ou raça entre escolares paulistanos(as). Caderno de Pesquisa, 37(132),759-799. http://publicacoes.fcc.org.br/index.php/cp/article/view/351/355

Rossato, Cesar \& Gesser, Verônica. (2001). A experiência da branquitude diante de conflitos raciais: estudos de realidades brasileiras e estadunidense. In: Eliane. Cavalleiro (Ed.), Racismo e anti-racismo na educação: repensando nossa escola (pp. 11-36). Selo Negro.

Sampaio, Sônia M. (2010). A Psicologia na educação superior: ausências e percalços. Em Aberto, 23(83), 95-105. https://doi.org/10.24109/21766673.emaberto.23i83.2253

Santos, Alessandro O. \& Schucman, Lia V. (2015). Desigualdade, relações raciais e a formação de psicólogo(as). Revista EPOS, 6(2), 117-140. http: // pepsic.bvsalud.org/scielo.php?script=sci_arttext\&pid=S2178700X2015000200007\&lng=pt\&tlng=pt.

Santos, Alessandro O.; Schucman, Lia V. \& Martins, Hildeberto V. (2012). Breve histórico do pensamento psicológico brasileiro sobre relações étnicoraciais. Psicologia: Ciência e Profissão, 32(spe), 166175. https://doi.org/10.1590/S1414-98932012000500012

Santos; Márcia A. P.; Nery, Joilda S.; Goes, Emanuelle F.; Silva, Alexandre; Santos, Andreia B. S.; Batista Luís E. \& Araújo, Edna M. (2020). População negra e Covid-19: reflexões sobre racismo e saúde. Estudos Avançados, 34(99), 225-244. https://doi.org/10.1590/s0103-4014.2020.3499.014

Schucman, Lia V. (2012). Entre o “encardido", o "branco" e o branquíssimo": raça, hierarquia e poder na construção da branquitude paulistana. Tese de Doutorado inédita, Universidade de São Paulo. http://www.ammapsique.org.br/baixe/encardido-branco-branquissimo.pdf

Silva, Marcos A. B. (2016). Discursos étnico-raciais proferidos por pesquisadores/as negros/as na pós-graduação: acesso, permanência, apoios e barreiras. Tese de Doutorado inédita, Pontifícia Universidade Católica de São Paulo. https://sapientia.pucs p. br/handle/handle/17137

Silva, Marcos A. B. \& Ribeiro, Maria S. (2019). Diversidade cultural nas políticas públicas: uma análise das Leis 10.639/03 e 11.645/08. Revista Exitus, 9(5), 77-101. https://doi.org/10.24065/2237-9460.2019v9n4ID1101

Silva, Maria L. (2020). Caderno Temático “III PSINEP - Articulação Nacional de Psicólogas/os Negras/os e Pesquisadoras/es”. Revista da Associação Brasileira De Pesquisadores/As Negros/As (ABPN), 12(Ed. Especi), 3-5. https://www.abpnrevista.org.br/index.php/site/article/view/1114

Silva, Maria L. \& Peruzzo, Maria O. S. (2020). Enfim...por que a Campanha saúde da população negra importa! Revista Da associação Brasileira De Pesquisadores/As Negros/As (ABPN), 12(Ed. Especi), 152-187. https://www.abpnrevista.org.br/index.php/site/article/view/1115

Silva, Marta L. (2014). Discursos de mães negras sobre educação e cuidado de crianças de até três anos de idade. Dissertação de Mestrado inédita, Pontifícia Universidade Católica de São Paulo. https://sapientia.pucs p. br/handle/handle/17080 
Silva, Paulo V. B.; Gomes, Nilma L. \& Régis, Kátia. (2018). Capítulo1- A Proposta e seus objetivos. In: Paulo V. B. Silva, Kátia Régis \& Shirley A. Miranda (Eds.), Educação das relações étnico-raciais: o estado da arte (pp. 21-32). NEAB-UFPR e ABPN.

Suleiman, Bianca B. (2014). Psicologia e Ensino das Relações Étnico-Raciais: uma experiência na formação de professores. Psicologia Escolar e Educacional, 18(2), 369-372. https://doi.org/10.1590/2175-3539/2014/0182809

Tavares, Jeane S. C.; Jesus Filho, Carlos A. A. \& Santana, Elisangela F. (2020). Por uma política de saúde mental da população negra no SUS. Revista Da associação Brasileira De Pesquisadores/As Negros/As (ABPN), 12 (Ed. Especi), 138-151. https://www.abpnrevista.org.br/index.php/site/article/view/1118

Tavares, Jeane S. C.; Kuratani, Sayuri M. A. (2019). Manejo Clínico das Repercussões do Racismo entre Mulheres que se "Tornaram Negras". Psicologia: Ciência e Profissão, 39, e184764. https://doi.org/10.1590/1982-3703003184764

Van Dijk, Teun. (2001). Critical discourse analysis. In: Deborah Schiffrin, Deborah Tannen \& Heidi E. Hamilton. The handbook of discourse analysis (pp. 352-371). Wiley Blackwell.

Veiga, Lucas M. (2019). Descolonizando a psicologia: notas para uma Psicologia Preta. Fractal: Revista De Psicologia, 31, 244-248. https://doi.org/10.22409/19840292/v31i_esp/29000

Vianna, Cintia C.; Benite, Anna M. C.; Figueiredo; Mércia O. B. S. \& Silva, A. N. (2020). Apresentação. Revista Da Associação Brasileira De Pesquisadores/As Negros/As $(A B P N), 12($ Ed. Especi),1-2.

https://www.abpnrevista.org.br/index.php/site/article/view/1119

Werneck, Jurema. (2016). Racismo institucional e saúde da população negra. Saúde e Sociedade, 25(3), 535-549. https://doi.org/10.1590/s0104-129020162610

\section{Marcos ANTONIO Batista da SiLVA}

Doutor em Psicologia Social pela Pontifícia Universidade Católica de São Paulo. Pósdoutorando no Centro de Estudos Sociais, Universidade de Coimbra. Integrante do projeto POLITICS - A política de antirracismo na Europa e na América Latina: produção de conhecimento, decisão política e lutas coletivas. (ERC-2016-COG725402). marcos.psico@yahoo.com.br https://orcid.org/0000-0003-2701-0316 


\section{IVANI FRANCISCO DE OLIVEIRA}

Mestra em Psicologia Social pela Pontifícia Universidade Católica de São Paulo. Supervisora de estágios da Universidade Cidade de São Paulo. Tem experiência na área de Psicologia, com ênfase em Psicologia Social.

ivani.oliveira.psi@gmail.com

https://orcid.org/0000-0002-8996-1304

\section{FINANCIACIAMENTO}

European Research Council(ERC-2016-COG-725402)

\section{FORMATO DE CITACIÓN}

Silva, Marcos Antonio Batista da \& Oliveira, Ivani Francisco de (2021). A relação entre racismo, saúde e saúde mental: Psicologia e educação antirracista. Quaderns de Psicologia, 23(3), e1753. https://doi.org/10.5565/rev/qpsicologia. 1753

\section{HISTORIA EDITORIAL}

Recibido: 26-01-2021

$1^{a}$ revisión: 16-04-2021

Aceptado: 02-05-2021

Publicado: 25-01-2022 